\title{
Sodium Silicate-catalyzed Multicomponent Synthesis of Pyridine Dicarbonitriles
}

\author{
Majid M. Heravi, ${ }^{*}$ Maliheh Khorshidi, Yahia. Sh. Beheshtia, and Bita Baghernejad \\ Department of Chemistry, School of Science, Azzahra University, Vanak, Tehran, Iran \\ ${ }^{*}$ E-mail:mmh1331@yahoo.com \\ Received August 2, 2009, Accepted March 24, 2010
}

Pyridine dicarbonitriles have been synthesized good yields via a one-pot multi-component reaction of aldehyde, malononitrile, and thiol in the presence of sodium silicate as a catalyst in ethanol.

Key Words: Pyridine dicarbonitriles, Multi-component reaction, One-pot, Sodium silicate

\section{Introduction}

In recant years, multicomponent reactions (MCRs) have become important tools in modern preparative synthetic chemistry because these reactions increase the efficiency by combining several operational steps without any isolation of intermediates or change of the conditions ${ }^{1,2}$ and MCRs have recently emerged as valuable tools in the preparation of structurally diverse chemical libraries of drug-like heterocyclic compounds. ${ }^{3-5}$

The pyridine nucleus is of considerable interest as this ring is the key constituent in a range of bioactive compounds, both naturally occurring and synthetic, and often of considerable complexity. ${ }^{6}$ The pyridine dicarbonitrile substructure was therefore chosen as a basic structural scaffold for the design of a reaction-based library. ${ }^{7}$ Thus, the synthesis of highly substituted pyridines has attracted much attention, and a number of procedures have been developed using a variety of protocols, such as hetero-Diels-Alder reaction of 3-siloxy-1-aza-1,3-butadienes with electron-deficient acetylenes ${ }^{8 \mathrm{a}}$ three-component condensation of aldehyde, malononitrile, and thiol ${ }^{8 b}$ ruthenium-catalyzed cycloisomerization of 3 -azadienynes ${ }^{8 c}$ Mannich reaction of aldehydes and iminium salts ${ }^{8 \mathrm{~d}}$ Vilsmeier-Haack reaction of $R$ hydroxyketenedithioacetals. ${ }^{8 \mathrm{e}}$ Among these, one of the very convenient approaches which attracted our attention is the threecomponent condensation of aldehyde, malononitrile, and thiol to the highly substituted pyridines developed by Evdokimov et al. ${ }^{\mathrm{bb}}$ Herein, we report a mild, practical and highly efficient procedure for the preparation of the title compounds using Sodium silicate as a catalyst at room temperature (Scheme 1).

To the best of our knowledge there are no reports on the synthesis of these compounds with 4-methyl thiophenol using Sodium silicate as the catalyst.

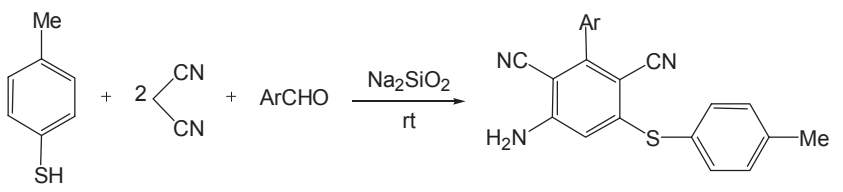

Scheme 1

\section{Results and Discussion}

In connection with our recent interested aimed at the development of efficient protocols for the preparation of biological active heterocycles, ${ }^{15-18}$ herein, we selected Sodium silicate as a new catalyst to synthesis of pyridine dicarbonitriles. The reaction of various aldehydes, 4-methyl thiophenol, malononitrile in the presence of Sodium silicate in ethanol afforded pyridine

Table 1. Synthesis of pyridine dicarbonitriles with deifferent aldehydes

\begin{tabular}{cccc}
\hline Entry & $\mathrm{Ar}$ & Product & Yield (\%) $^{a}$ \\
\hline 1 & $\mathrm{C}_{6} \mathrm{H}_{5}$ & $4 \mathrm{a}$ & 78 \\
2 & $4-\mathrm{Cl}-\mathrm{C}_{6} \mathrm{H}_{4}$ & $4 \mathrm{~b}$ & 82 \\
3 & $3-\mathrm{Cl}_{2} \mathrm{C}_{6} \mathrm{H}_{4}$ & $4 \mathrm{c}$ & 81 \\
4 & $4-\mathrm{Br}_{-} \mathrm{C}_{6} \mathrm{H}_{4}$ & $4 \mathrm{~d}$ & 80 \\
5 & $3-\mathrm{Br}_{-} \mathrm{C}_{6} \mathrm{H}_{4}$ & $4 \mathrm{e}$ & 79 \\
6 & $3-\mathrm{NO}_{2}-\mathrm{C}_{6} \mathrm{H}_{4}$ & $4 \mathrm{f}$ & 78 \\
7 & $4-\mathrm{NO}_{2}-\mathrm{C}_{6} \mathrm{H}_{4}$ & $4 \mathrm{~g}$ & 80 \\
8 & $4-\mathrm{CH}_{3} \mathrm{O}-\mathrm{C}_{6} \mathrm{H}_{4}$ & $4 \mathrm{~h}$ & 82 \\
\hline
\end{tabular}

${ }^{a}$ Yields were analyzed by GC.

Table 2. Synthesis of $4 \mathrm{a}$ in the presence of different solvents using Sodium silicate as a catalyst

\begin{tabular}{ccc}
\hline Entry & Solvent & ${\text { Yield }(\%)^{a}}^{a}$ \\
\hline 1 & $\mathrm{THF}$ & 68 \\
2 & $\mathrm{CH}_{3} \mathrm{OH}$ & 72 \\
3 & $\mathrm{CH}_{3} \mathrm{CN}$ & 76 \\
4 & $\mathrm{CHCl}_{3}$ & 70 \\
5 & $\mathrm{C}_{2} \mathrm{H}_{5} \mathrm{OH}$ & 78 \\
\hline
\end{tabular}

${ }^{a}$ Yields were analyzed by GC.

Table 3. Synthesis of $4 \mathrm{a}$ using various catalysts

\begin{tabular}{ccc}
\hline Entry & Catalyst & ${\text { Yield }(\%)^{a}}^{a}$ \\
\hline 1 & $\mathrm{H}_{6}\left[\mathrm{P}_{2} \mathrm{~W}_{18} \mathrm{O}_{62}\right]$ & 10 \\
2 & $\mathrm{P}-\mathrm{TSA}$ & 50 \\
3 & $\mathrm{KHSO}_{4}$ & 30 \\
4 & $\mathrm{Na}_{2} \mathrm{SiO}_{3}$ & 80
\end{tabular}

${ }^{a}$ Yields were analyzed by GC. 
dicarbonitriles at room temperature in good yields (Table 1).

We performed the effect of various solvents on the synthesis of $4 \mathrm{a}$. This reaction was carried out in various solvents and the best results in terms of yield and time obtained in ethanol (Table 2).

In each reaction, the yield is a function of the reaction time and the best time for all reactions was completed after $1 \mathrm{~h}$. The reactions proceeded well with $5 \mathrm{~mol} \%$ of catalyst and use of an increased amount of catalyst does not make much difference.

In order to show the merit of the present work, we compared the result of the synthesis of these compounds in the presence of various catalysts but the best results obtained with Sodium silicate (Table 3 ).

In conclusion, we have described a highly efficient procedure for the preparation of pyridine dicarbonitriles via a condensation reaction of various aldehydes, malononitrile, and thiol using sodium silicate as a catalyst. The procedure offers several advantages including high yields, operational simplicity, cleaner reaction, minimal environmental impact, and low cost, which make it a useful and attractive process for the synthesis of these compounds

\section{Experimental}

All products were characterized by mp, IR, ${ }^{1} \mathrm{H}$ NMR and GC/ MS. Melting points were measured by using the capillary tube method with an electro thermal 9200 apparatus. ${ }^{1} \mathrm{H}$ and ${ }^{13} \mathrm{C}$ NMR spectra were recorded on a Bruker DRX Avance spectrometer at 500 and $125 \mathrm{MHZ}$, respectively, with $\mathrm{CDCl}_{3}$ as solvent. IR spectra were recorded from $\mathrm{KBr}$ disk on the FT-IR Bruker Tensor 27. GC/MS spectra were recorded on an Agilent Technologies 6890 network GC system and an Agilent 5973 network Mass selective detector. Thin layer chromatography (TLC) on commercial aluminum-backed plates of silica gel, 60 F254 was used to monitor the progress of reactions. All products were characterized by spectra and physical data.

Typical procedure for preparation of pyridine dicarbonitriles. To a magnetically stirred solution of aldehyde (1 mmol), 4methyl thiophenol (1 mmol) and $\mathrm{Na}_{2} \mathrm{SiO}_{3}(5 \mathrm{~mol} \%)$ in $(5 \mathrm{~mL})$ was added malononitrile ( $2 \mathrm{mmol}$ ) and stirring was continued for $1 \mathrm{~h}$. The precipitate was filtered and washed with ethanol to give product.

4b: ${ }^{1} \mathrm{H}$ NMR $\left(\mathrm{CDCl}_{3}, 500 \mathrm{MHz}\right) \delta_{\mathrm{H}} 2.47(3 \mathrm{H}, \mathrm{s}), 7.30-7.58$ (9H, m, arom), $7.59(2 \mathrm{H}, \mathrm{s}) .{ }^{13} \mathrm{C} \mathrm{NMR}\left(\mathrm{CDCl}_{3}, 125 \mathrm{MHz}\right) \delta_{\mathrm{C}}$ 21.85, 87.46, 96.07, 115.08, 115.49, 123.81, 129.89, 130.33, $130.62,131.99,136.08,137.83,140.85,157.49,159.68,170.19$.

\section{References}

1. Zhu, J.; Bienayme, H. Multicomponent Reactions; Wiely-VCH: Weinheim: 2005.

2. Litvinov, V. P. Russ. Chem. Rev. 2003, 72, 69.

3. Ugi, I.; Dömling, A.; Hörl, W. Endeavour. 1994, 18, 115.

4. Tietze, L. F.; Modi, A. Med. Res. Rev. 2000, 20, 304.

5. Ugi, I.; Dömling, A.; Werner, B. J. Heterocycl. Chem. 2000, 37, 647.

6. Boger, D. L.; Nakahara, S. J. Org. Chem. 1991, 56, 880.

7. Reddy, T. R. K.; Mutter, R.; Heal, W.; Guo, K.; Gillet, W. J.; Pratt, S.; Chen, B. J. Med. Chem. 2006, 49, 607.

8. (a) Fletcher, M. D.; Hurst, T. E.; Miles, T. J.; Moody, C. J. Tetrahedron 2006, 62, 5454. (b) Evdokimov, N. M.; Magedov, I. V.; Kireev, A. S.; Kornienko, A. Org. Lett. 2006, 8, 899. (c) Movassaghi, M.; Hill, M. D. J. Am. Chem. Soc. 2006, 128, 4592. (d) Winter, A.; Risch, N. Synthesis 2003, 2667. (e) Thomas, A. D.; Asokan, C. V. Tetrahedron Lett. 2002, 43, 2273.

9. (a) Pan. J. F.; Chen, K. Tetrahedron Lett. 2004, 45, 2541. (b) Radha Krishna, P.; Maryurani, A.; Kannan, V.; Shasma, G. V. M. Tetrahedron Lett. 2004, 45, 183.

10. (a) Sheen, W. C.; Lazanov, M.; Rejic, O. Tetrahedron Lett. 2003 , 44, 6943. (b) Shreh, W. C.; Loo, M.; Lazaneer, M.; Rejuc, O.; Blacklock, T. J. Tetrahedron Lett. 2003, 44, 4563.

11. Takkewaki, T.; Beck, L. W.; Danis, M. E. Micropor. Mesopor. Mater. 1999, 33, 197.

12. Veeraraghavan, P.; Michael, R.; Rudd, T.; Reddy, M. V. R. Tetrahedron Lett. 1999, 40, 3819.

13. Basavaiah, D.; Bharathi, T. K.; Gawzeswaie, V. V. L. Tetrahedron Lett. 1987, 28, 4352.

14. Basavaiah, D.; Gawriswari; V. V. L.; Bahara thine, T. K. Tetrahedron Lett. 1987, 28, 4591.

15. Bamoharram, F. F.; Heravi, M. M.; Roshani, M.; Gharib, A.; Jahangir, M. Appl. Catal. 2006, 302, 42.

16. Heravi, M. M.; Hekmatshoar, R.; Pedram, L. J. Mol. Catal. A: Chem. 2005, 89, 231.

17. Heravi, M. M.; Bakhtiari, K.; Oskooie, H. A. J. Chin. Chem. Soc. 2007, 54, 579.

18. Heravi, M. M.; Oskooie, H. A.; Baghernejad, B. J. Chin. Chem. Soc. 2007, 54, 767. 